\title{
Hepatoencephalopathy due to combined oxidative phosphorylation defect type 1
}

INSERM

\section{Source}

INSERM. (1999). Orphanet: an online rare disease and orphan drug data base.

Hepatoencephalopathy due to combined oxidative phosphorylation defect type 1.

ORPHA:137681

Hepatoencephalopathy due to combined oxidative phosphorylation deficiency type 1 is a rare, inherited mitochondrial disorder due to a defect in mitochondrial protein synthesis characterized by intrauterine growth retardation, metabolic decompensation with recurrent vomiting, persistent severe lactic acidosis, encephalopathy, seizures, failure to thrive, severe global developmental delay, poor eye contact, severe muscular hypotonia or axial hypotonia with limb hypertonia, hepatomeg aly and/or liver dysfunction and/or liver failure, leading to fatal outcome in severe cases. Neuroimaging abnormalities may include corpus callosum thinning, leukodystrophy, delayed myelination and basal gang lia involvement. 